\title{
Planned Pharmacologic Target Entrez Gene Identifier
}

National Cancer Institute

\section{Source}

National Cancer Institute. Planned Pharmacologic Target Entrez Gene Identifier. NCI Thesaurus. Code C147515.

The accession number maintained within the Entrez Gene database for the assumed gene target of the pharmacologic intervention. 